\section{POS0933 TREATMENT ACCESS AND ADHERENCE DURING SOCIAL PREVENTIVE AND MANDATORY ISOLATION IN ARGENTINIAN PATIENTS WITH SPONDYLARTHRITIS}

C. Airoldi ${ }^{1}$, V. Martire ${ }^{2}$, M. S. Gálvez Elkin ${ }^{3}$, P. Girard Bosch ${ }^{2}$, V. Duarte ${ }^{4}$, S. Scarafia ${ }^{5}$, F. Sommerfleck ${ }^{6}$, M. Machado Escobar ${ }^{7}$, N. Callahuara ${ }^{8}$, J. Alcivar Navarrete $^{9}$, M. A. Medina ${ }^{9}$, E. Buschiazzo ${ }^{10}$, M. Cosatti ${ }^{11}$, R. Garcia Salinas ${ }^{12}$, E. Saturansky ${ }^{6}$, V. Cosentino ${ }^{13}$, D. Vila ${ }^{14}$, M. J. Gamba ${ }^{15}$, E. Kerzberg ${ }^{13}$, G. P. Pendon ${ }^{16}$, D. Zelaya ${ }^{13}$, R. Águila Maldonado ${ }^{17}$, L. Abbas ${ }^{18}$, R. Nieto ${ }^{1}$, S. Nasi ${ }^{19}$, R. Luis ${ }^{13}$, M. L. Acosta Felquer ${ }^{20}$, M. Benegas ${ }^{6}$ on behalf of Grupo de estudio de la Sociedad Argentina de Reumatología de Espondiloartritis axial yArtritis reactiva (GESAR EspAax-ARe). ${ }^{1}$ Hospital Provincial, Rheumatology, Rosario, Argentina; ${ }^{2}$ Instituto Médico Platense, Rheumatology, La Plata, Argentina; ${ }^{3}$ Instituto Cardiológico Santiago del Estero, Rheumatology, Santiago del Estero, Argentina; ${ }^{4}$ Monte Grande Clinic, Rheumatology, Buenos Aires, Argentina; ${ }^{5}$ Hospital Municipal San Cayetano, Rheumatology, Buenos Aires, Argentina; ${ }^{6}$ Hospital Mendez, Rheumatology, Buenos Aires, Argentina; ${ }^{7}$ Hospital Eva Perón, Rheumatology, Tucumán, Argentina; ${ }^{8}$ Hospital Rivadavia, Rheumatology, Buenos Aires, Argentina; ${ }^{9}$ Hospital Tornú, Rheumatology, Buenos Aires, Argentina; ${ }^{10}$ Hospital Sr. Del Milagro, Rheumatology, Salta, Argentina: ${ }^{11}$ CEMIC, Rheumatology, Buenos Aires, Argentina; ${ }^{12}$ Hospital Italiano de La Plata, Rheumatology, La Plata, Argentina; ${ }^{13} \mathrm{Hospital}$ Ramos Mejía, Rheumatology, Buenos Aires, Argentina; ${ }^{14}$ Centro Médico Ginecológico, Rheumatology, Buenos Aires, Argentina: ${ }^{15}$ Hospital Posadas, Rheumatology, Buenos Aires, Argentina; ${ }^{16} \mathrm{Hospital}$ Ricardo Gutierrez, Rheumatology, La Plata, Argentina; ${ }^{17}$ Hospital San Martin, Rheumatology, La Plata, Argentina; ${ }^{18}$ PSORIAHUE, Rheumatology, Buenos Aires, Argentina; ${ }^{19}$ Hospital El Carmen, Rheumatology, Mendoza, Argentina; ${ }^{20}$ Hospital Italiano de Buenos Aires, Rheumatology, Buenos Aires, Argentina

Background: Access to high-cost treatments is especially limited in low-resource countries. This issue is becoming stronger today given the health and economic crisis caused by the SARS-CoV2 pandemic. There are no reports in our country on limitations to access and adherence to treatment in patients with Spondyloarthritis $(\mathrm{SpA})$ during social preventive and mandatory isolation.

Objectives: Evaluate access and adherence to treatment in patients with Spondyloarthritis during social preventive and mandatory isolation.

Methods: Patients with axial spondyloarthritis (axSpA) radiological (r-axSpA), non-radiological (nr-axSpA) and peripheral spondyloarthritis ( $\mathrm{pSpA}$ ), according to ASAS criteria and psoriatic arthritis (PSA) according to CASPAR criteria, were included. Sociodemographic data, comorbidities, disease activity and treatments were collected at baseline. Data on treatment discontinuation, medical attention for suspected COVID-19 disease, RT-qPCR for SARS-CoV-2 detection and outcome of COVID-19 disease were collected from April to September 2020. Numerical variables were summarized as means and standard deviations (SD) or as medians and interquartiles 25-75 (IQ 25-75).

Results: 320 patients were included, $55 \%$ were male, with a mean age of 50 years (SD 13), 21.6\% had diagnosis of $r$-axSpA, 6.9\% nr-axSpA, 6.9\% pSpA, and $64.7 \%$ PsA. Disease duration was 11 (IQ 5-16) years and activity parameters were as follow: BASDAI 3.65 (SD 3), BASFI 3 (1.5-9), PASI 0.3 (0-7), BSA 0.2 (0-6). 14 (4.4\%) patients with COVID-19 disease were reported, 10 were confirmed by positive RT-qPCR and 4 by symptoms and history of close contact with SARS patients. $4(28.6 \%)$ received anti TNF ( 3 adalimumab, 1 certolizumab), $4(28.6 \%)$ anti IL17 (3 secukinumab and 1 ixekizumab), 8 (57\%) methotrexate (MTX) and 2 (14\%) leflunomide (LF). Among the 320 patients included, 59 (18.4\%) discontinued at least one treatment during follow-up. The discontinued medications were: adalimumab (16), MTX (15), secukinumab (9), etanercept (6), certolizumab(4), ustekinumab (3), NSAIDs (2), apremilast (1), golimumab (1), ixekuzumab (1), LF (1), MTX plus LF (1). The main reason for treatment discontinuation was drug shortage: $36(62 \%)$, followed by patient's decision: 12 $(21 \%)$ and medical indication: 11 (17\%). Of the 36 patients who discontinued due to shortage, 11 received adalimumab, 8 secukinumab, 5 MTX, 3 etanercept, 3 certolizumab, 3 ustekinumab, 2 NSAIDs and 1 golimumab.

Conclusion: In our Argentinian cohort of patients with SpA, drug shortage was the main reason for treatment discontinuation. The SARS-CoV2 pandemic exposed limitations to access to treatment for patients with SpA.

Disclosure of Interests: None declared

DOI: 10.1136/annrheumdis-2021-eular.3147

POS0934

\section{BIOLOGICAL THERAPY IN UVEITIS ASOCIATED TO AXIAL SPONDYLOARTHRITIS. SINGLE CENTER UNIVERSITY STUDY}

A. Herrero-Morant ${ }^{1}$, I. González-Mazón ${ }^{1}$, V. Calvo-Río ${ }^{1}$, J. Rueda-Gotor ${ }^{1}$, M. Á. González-Gay ${ }^{1}$, R. Blanco ${ }^{1} .{ }^{1}$ Hospital Universitario Marqués de Valdecilla, Rheumatology, Santander, Spain
Background: Uveitis is the most frequent extraarticular manifestation of axial Spondyloarthritis (axSpA). Effects of Biological Therapy (BT) on uveitis associated to axSpA are contradictory (1-3).

Objectives: To assess in uveitis associated to $\operatorname{axSpA}$ a) frequency and features of uveitis, and b) efficacy and relation of BT in a single-center university study. Methods: Observational study from a cohort of 301 consecutive unselected patients with axSpA classified according to the Assessment of SpondyloArthritis International Society criteria. Episodes of uveitis were analyzed before and after BT initiation. Likewise, uveitis incidence rate (episodes/100 patients/year) at baseline and after first BT was calculated.

Results: Uveitis was observed in 44 (25 men/19 women) out of 301 (14.6\%) patients. Mean age was $45.6 \pm 10.3$ years. Demographic and clinical features in patients who developed uveitis and those that did not are summarized in Table 1. After $18.6 \pm 10.4$ years of follow-up, $44(14.6 \%)$ patients suffered from at least one episode of uveitis. Uveitis was anterior and acute in all cases and unilateral in $37(84.1 \%)$ patients. Mean anterior chamber cells was 1.7 \pm 1.2 cells.

Per episode of uveitis, 20 patients received BT with: secukinumab (SECU) ( $n=7$, $35 \%)$, adalimumab $(n=6,30 \%)$, golimumab $(n=3,15 \%)$, infliximab $(n=2,10 \%)$ certolizumab $(n=1,5 \%)$, and etarnecept $(E T N)(n=1,5 \%)$. Before the initiation of BT, patients treated with SECU developed 29.7 episodes/100 patients/year while those treated with monoclonal anti-TNF $\alpha 16.3$ episodes/100 patients/year and patients with ETN 5.8 episodes/100 patients/year. After $5.9 \pm 3.7$ years of follow-up, patients treated with SECU developed 16.1 episodes/100 patients/ year while those treated with monoclonal anti-TNF $\alpha .6$ episodes/100 patients/ year and patients with ETN 0 episodes/100 patients/year (Figure 1). No serious adverse effects were observed.

Conclusion: Uveitis was observed in $14.6 \%$ of axSpA. Most of them were HLAB27 positive. Acute, anterior and unilateral was the most frequent pattern of uveitis in axSpA. There was a similar decrease in incidence rate between patients treated with SECU and those treated with monoclonal anti-TNF $\alpha$.

\section{REFERENCES:}

[1] Deodhar AA, et al. ACR Open Rheumatol. 2020; 2:294-299.

[2] Roche D, et al [abstract]. Arthritis Rheumatol 2019; 71 (suppl 10).

[3] Lindström U, et al Annals of the Rheumatic Diseases 2020;79:9-10.

Table 1. Main general features and differences between patients with and without uveitis.

\begin{tabular}{|c|c|c|c|c|}
\hline & $\begin{array}{l}\text { Overall } \\
n=301\end{array}$ & $\begin{array}{l}\text { Uveitis } \\
n=44\end{array}$ & $\begin{array}{l}\text { Non uveitis } \\
n=257\end{array}$ & $p$ \\
\hline Age, years (mean $\pm S D)$ & $44.9 \pm 11.8$ & $45.6 \pm 10.3$ & $44.8 \pm 12.1$ & 0.47 \\
\hline Gender, $n(m / w)(\%)$ & $\begin{array}{c}179 / 122 \\
(59.5 / 40.5)\end{array}$ & $\begin{array}{c}25 / 19 \\
(56.8 / 43.2)\end{array}$ & $\begin{array}{c}154 / 103 \\
(59.9 / 40.1)\end{array}$ & 0.71 \\
\hline HLAB27 positive,n (\%) & $190(63.1)$ & $37(84.1)$ & $153(60.0)$ & 0.00 \\
\hline Follow-up of axSpA, year $(\operatorname{mean} \pm S D)$ & $13.5 \pm 11.2$ & $18.6 \pm 10.5$ & $12.6 \pm 11.1$ & 0.33 \\
\hline Family history, $\mathrm{n}(\%)$ & $84(27.9)$ & $15(34.1)$ & $69(27.2)$ & 0.35 \\
\hline r-axSpA, n (\%) & $217(72.1)$ & $36(81.8)$ & $181(70.4)$ & 0.12 \\
\hline nr-axSpA, n (\%) & 84 (27.9) & $8(18.2)$ & $76(29.6)$ & 0.12 \\
\hline Enthesitis, n (\%) & $108(35.9)$ & $14(31.8)$ & $94(36.6)$ & 0.54 \\
\hline Peripheral arthritis, $\mathbf{n}(\%)$ & $96(31.9)$ & $12(27.3)$ & $84(32.7)$ & 0.47 \\
\hline Psoriasis, n (\%) & 35 (11.6) & $6(13.6)$ & $29(11.3)$ & 0.65 \\
\hline Inflammatory bowel disease, $\mathrm{n}(\%)$ & $22(7.3)$ & $2(4.5)$ & $20(7.8)$ & 0.45 \\
\hline Hip involvement, $\mathbf{n}(\%)$ & $20(6.6)$ & $3(6.8)$ & $17(6.6)$ & 0.96 \\
\hline Dactylitis, n (\%) & $17(5.7)$ & $3(6.8)$ & $14(5.4)$ & 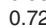 \\
\hline Cardiovascular event, n (\%) & $7(2.3)$ & $1(2.3)$ & $6(2.3)$ & 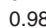 \\
\hline
\end{tabular}

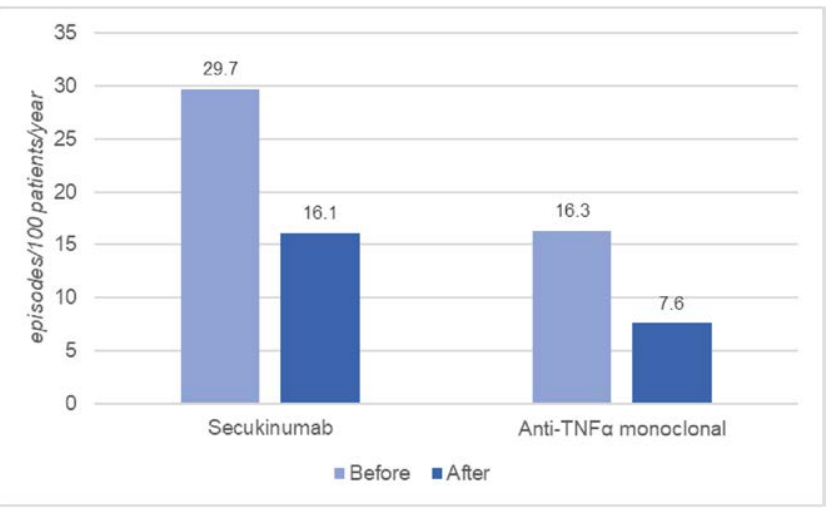

Figure 1. Uveitis incidence rate before and after biological therapy. 